\title{
The Complex Roles of Relatives in End-of-Life Decision- Making: An Ethical Analysis
}

\author{
Stella Reiter-Theil $\cdot$ Marcel Mertz $\cdot$ Barbara Meyer-Zehnder
}

\section{Introduction and Research Questions}

Today, good care for patients at the end-of-life (EoL) is often evaluated according to the principles of palliative care (WHO, 2006). One of the predominant ideas is to involve the relatives in the process of care and decision-making and to accept them as part of the "unit of care." As members of the unit of care, relatives should enjoy paramount significance (Reiter-Theil, 2003). Whereas this seems to be evident for parents of pediatric patients despite many difficulties, especially with severely ill infants (Hentschel, Linder, \& Krüger, 2006), it needs to be emphasized for the loved ones of adult patients. The involvement of relatives is not only relevant for the clinical and psychological quality of care; the way relatives are involved in EoL care and in making treatment decisions also has normative impact. Legal regulations and ethical guidelines set national standards of when and how relatives should receive information and participate in making treatment decisions. Also, the question of a moral right of relatives to be involved in decision-making will be discussed (Arnold and Kellum, 2003).

It has often been said that Europe is maintaining a stronger paternalism as compared to the U.S. focus on patient autonomy (Giannini, Pessina, \& Tacchi, 2003; Levy, 2001; Gerlach, Dhainut, \& Harbarth et al., 2003; Eidelmann and Jakobsen, 1998; Reich and Jecker, 1995; Reiter-Theil, 1998; Zientek, 2005). This was also concluded by Fassier et al. (Fassier, Lautrette, \& Ciroldi et al., 2005) in their review of empirical studies on the European situation. ${ }^{2}$ This issue is connected with the vision of the relatives' roles in

Prof. Dr. Stella Reiter-Theil, Director, Institute for Applied Ethics and Medical Ethics, University of Basel, Missionsstr. 21, CH-4055 Basel, Switzerland; e-Mail: s.reiter-theil@unibas.ch.

Marcel Mertz, Institute for Applied Ethics and Medical Ethics, University of Basel, Missionsstr. 21, CH4055 Basel, Switzerland; e-mail: Marcel.Mertz@unibas.ch.

Barbara Meyer-Zehnder, Institute for Applied Ethics and Medical Ethics, University of Basel, Missionsstr. 21, CH-4055 Basel, Switzerland; email: Barbara.Meyer@unibas.ch. 
cases where the patient is unable to express himself: the more paternalistically clinical decision-making is organized by the staff, the less the family of the patient will be invited and able to give their opinions on the patient's wishes. Insofar as respect for the patient's perspective and wishes is followed as a guiding principle in practice, the observations and considerations of relatives will be significant for understanding what an unconscious or incapacitated patient might wish.

Swiss federal law states that informed consent is a prerequisite for treatment. However, it is less accurately regulated what procedure should be carried out if the patient is incapacitated. Presently, a gray zone of pragmatic tolerance leaves space for physicians to decide on their own or to influence whether a substitute decision-maker will be formally appointed by a court, or whether an informal approach of decision-making on the grounds of medical indication and best interest standards will be utilized. In situations where neither a valid patient wish can be obtained, nor an advance directive or an authorized substitute decision-maker are available, the treatment decision remains with the physician in charge. In the case of patients unable to give informed consent, the physician should, according to national ethics guidelines (SAMS, 2005; SAMS, 2004; Bartels, Parker, \& Hope et al., 2005), act on the patient's "presumed wishes" when making any treatment decision. The proposed course of action should be in agreement with the presumed patient wishes. Relatives will be the central source of information to gain better insight into the situation. Even though the criterion of the patient's "presumed wishes" is a soft one and not clearly defined by the guidelines, there seems to be consensus among Swiss clinicians and the population that the relatives of the patient should be involved in determining the "presumed wishes".

This viewpoint is reflected in the draft of the revision of the Civil Code ${ }^{3}$ that has been initiated to give patients' rights, advance directives, and authorized substitute decision-makers a stronger position, in addition to strengthening the role of the relatives. Legally, relatives of adult, unconscious, sedated, or demented patients do not have a "right" to make treatment decisions for the patient unless they have been authorized to act as a substitute in advance by the patient or in an acute case by the court. Officially, it is considered incorrect, we may call it a normative error, for clinicians to ask the family: "What do you prefer regarding the treatment of your family member?" The "normative error" is even more severe in EoL care and decisions on life-sustaining measures. However, this kind of approach does occur as personal communications and observations have shown. Furthermore, the issue of confidentiality is related to this topic. Legally, clinicians should give information to relatives only with the 
patient's permission. Yet in end-of-life care, advance directives or authorizations of substitute decision-makers are not only frequently unavailable, but in most cases, staff cannot rely on any permission to waive confidentiality. The general expectation of relatives to be involved is based on assumptions that are incompatible with the premises of the present legal situation in Switzerland. However, some of the ethics guidelines (SAMS, 2004) as well as the planned revision of the Civil Code point in the direction of lowering the threshold to involve and to inform relatives as "significant others". Although confidentiality is an important issue to clarify, in our study we focused on the role of relatives in clinical decision-making because this has even greater practical relevance and needs stronger justification than the sharing of information. The study refers to case deliberation in a clinical unit that engages in ongoing efforts to implement procedural rules of ethical decision-making. We had the opportunity to carry out a mixed research strategy to yield clinically authentic observations and data. Data was analyzed descriptively and discussed ethically regarding four questions:

1. What are the most important ethical and practical issues in situations where relatives are, or should be, involved in EoL decision-making (Reiter-Theil, 2003)?

2. What kind of "authority" do or should relatives have in these situations?

3. How does, or should, the clinical team handle the identified challenges (Hurst, Perrier, \& Reiter-Theil et al., 2006)?

4. What kind of support can we suggest for clinical teams to cope with the challenges (Reiter-Theil, 2004)?

\section{Methods and Approaches}

The paper uses three empirical samples. First, an overview of a systematic case-series of ten patients treated in a surgical intensive care unit, which is a sub-sample of a larger set of case series. Second, one selected case study, and third, the analysis of selected quotes from the discussion of this case using verbatim transcripts. The results reflecting the relatives' involvement in EoL treatment decision-making were gained from these sources and submitted to ethical analysis. The method of case documentation followed the concept of the "Embedded Researcher" (Reiter-Theil, 2004) and was developed as an innovative approach to gather clinically authentic and ethically relevant data in a standardized way providing valid insight into the EoL decision-making process (Meyer-Zehnder, Pargger, \& Reiter-Theil, 2007). The systematic series of ten randomly selected cases was documented on a surgical intensive care unit in Switzerland. The only criterion of inclusion was that the care team, at some point during the course of illness 
considered withholding or withdrawing a treatment. An ethical case analysis using the "Embedded Researcher" approach has been published (Bühler and Reiter-Theil, 2004).

To collect medically as well as ethically relevant information, a documentation questionnaire consisting of three parts was developed. The observer's (Embedded Researcher's) subjective assessment and freedom of interpretation was minimized using a systematic procedure. The questionnaire enabled the researchers to answer ethically relevant questions about the patient's case history without needing further interpretation by a clinician. A case was closed when the patient died or was transferred to another ward. The documentation questionnaire was filled out in collaboration with the doctor in charge.

In addition to the detailed case material from the documentation, the paper used quotes from the so called "table-round", a daily meeting of all the clinical staff from the intensive care unit (Meyer-Zehnder, Pargger, \& Reiter-Theil, 2007). This approach offered a unique insight into the discussions and the decision-making in daily routine regarding the individual patient on the ward. With the permission of all team members, the conversations were tape-recorded followed by verbatim transcription and content analysis (Mayring, 2000). To our knowledge, no publications exist that describe this kind of "insider perspective" using systematic methods rather than anecdotal comments. The combination of the clinical-ethical case series and the analysis of transcripts of the table rounds allowed for interesting comparisons between what was actually done (case documentation) and what was discussed (table rounds).

Finally, we used the material to raise and analyze ethical questions and to develop conclusions. To identify and analyze ethical issues regarding the involvement of relatives, a conceptual approach to clarify the possible roles of relatives-i.e., their "authority"-is necessary, especially regarding expectations, rights, and obligations towards the patient, the involved clinical staff, and the decision-making process itself. The model utilized here will be described in the next section.

\section{Theoretical and Conceptual Basis}

The structuring and processing of the material relied on several sources of ethics, law, and guidelines. These reflect the international discourse and the national specificities of Switzerland (which are similar to other European countries, especially Germany). Explicit reference was made to respect for autonomy of the patient as one of the four major principles of health care ethics (Beauchamp and Childress, 2001), yet not in the form of the explicitly 
articulated wishes of the patient, or of informed consent, as the patients of our sample were no longer able to formulate preferences due to their medical condition. We referred to the voices of the relatives as an approach towards guessing the patient's "presumed wishes" and studied how this very common, but standardized objective is practiced. Issues of substitute decision-making whether formally established or not are also discussed. Complementary to respect for autonomy and the patient's wishes, the best interest standard was considered in case analysis.

Ethical principles and ethics guidelines share the reputation that they do not present hard and fast criteria, but are soft criteria with sometimes very lengthy considerations. Nevertheless, ethical guidelines are still considered to be somewhat more practical than ethical principles, which are often criticized for being too abstract and remote in practice (Bartels, Parker, \& Hope et al., 2005).

A theoretical analysis of which competences and abilities relatives do or should have is necessary and of paramount ethical significance. Therefore, the notion of "authority" will be introduced to provide a concept for understanding the complex interaction between abilities, exertion of these abilities, and (moral) rights concerning the involvement of relatives. As "authority" is often perceived in a pejorative or formal way (Agich, 1995), the following reflections are necessary to appreciate that this concept may have further meanings. As Agich explains, the common understanding of "authority" as "being in authority" often relates to having executive authority, "one [that] has the right or power to act for or on someone else" (Agich, 1995). However, this narrow understanding of authority does not account for more informal kinds of authority that seem to be more relevant for our topic here. For example, "social role authority" reflects the subtle social acknowledgement or acceptance of an agent in question, based on the personal skills that the agent brings to the function of the role (e.g., a physician, a teacher, a lawyer, or an ethicist) (Agich, 1995). Obviously, this is not identical with the classical Weberian understanding of "authority" as a rational or legal type of Herrschaft (power) ${ }^{4}$ (Weber, 1999), based on formal laws, i.e., bureaucratic and legitimate use of power, or in the words of Bochensui (1974), deontic authority, which denotes the capability of superiors to give orders or instructions to subordinates, e.g., to change behavior. Neither is a broader understanding of "social role authority" similar to other ideal types of Weber, such as the charismatic or the traditional type of Herrschaft, where the mere faith in a hero-like person (or a "prophet") or the faith in traditions respectively is sustaining Herrschaft.

The most important difference is that authority does not automatically signify the executive power or (mis)use of power as suggested by the more 
common understandings of the word. Authority in decision-making has more subtle and informal character and is similar to social acceptance, trust, and competence, rather than to executive power. (Yet, competence and knowledge certainly can produce power-relationships [e.g., Foucault, 1991].) Accordingly, "authority" here is defined as having a potential, i.e., capability of a specific type that can be exerted for decision-making; this potential may have an epistemic nature (knowledge-related) or practical nature. As a conceptual basis, we suggest a tentative typology of authority describing the roles that relatives may have or should have in situations where the patient wishes are not known, but have to be hypothesized or reconstructed.

\section{A Typology of Authority}

It may be uncommon to refer to the roles of relatives using the terminology of "authority". Especially in end-of-life care, relatives are in an ambiguous position: often they act as "significant others" of the patient and as an important resource of support, while at the same time frequently feel helpless and suffer from grief and loss. In addition, medical complexity may contribute to the feeling of being overwhelmed and unable to respond adequately to the demands. Nevertheless, many relatives feel or even claim that they have a right to be involved and should have a say in what happens to their severely ill family member. From an ethical perspective, relatives may not only have the right, but the obligation to be involved and make their voice heard to the clinicians in the interest of the patient-with or without the formal authorization of a living will or a court order. They may be convinced that they have specific knowledge to share and also competence to evaluate and choose options, which is a view shared by many clinicians. This can be understood as a role connected to certain kinds of authority, which will be analyzed in more detail later. How adequately to involve relatives raises questions and concerns about the do's and don'ts as well as about potential misconceptions surrounding the issue.

\section{Three dimensions of authority}

We propose a definition of "authority" that covers three dimensions: the ability to do something, the right to do something, and the involvement in doing something. Ability regards competence and knowledge as far as it is related to decision-making (both epistemic and practical) $;{ }^{5}$ the right addresses the moral and legal claim to be involved in decision-making (deontic), which falls into the domain of ethical and normative justification. ${ }^{6}$ Involvement means the actual contribution to decision-making (ontic), which can be hindered by practical, e.g., procedural or institutional, circumstances. 
In the "ideal" case, all three dimensions of authority are present and no dimension is under- or overvalued. What we call "incomplete constellations" are situations where one of the dimensions is under-represented leading to inconsistencies in the role of the relatives. The interaction of the three dimensions can be visualized in a three-dimensional graph, where the $\mathrm{x}, \mathrm{y}$, and $\mathrm{z}$ axes express degrees of ability, right, and involvement. Likewise, potential or factual limitations (e.g., legal aspects; see the "right to"-axis) of one or more dimensions are visualized. Ideally the axes should be balanced, and should have a sufficiently high degree to be relevant (i.e., the three axes could be balanced even if all three dimensions have a zero-degree). If one of the axes is over- or undervalued, this may lead to inconsistencies in the relatives' involvement in decision-making.

\section{Types of authority}

The following typology of authority is a tentative model. ${ }^{7}$ It has been developed in two ways: 1) inductively, on the basis of case material and 2) deductively, from general philosophical considerations (in reference to the work of Marcel Mertz).

Authority of Knowledge (AK). Our understanding of authority of knowledge is similar to what Agich calls epistemic authority: "Epistemic authority is authority in a field of knowledge, and arises, as a social institution, from the dual recognition both that we and others have knowledge and that others have knowledge that we do not have" (Agich, 1995, p. 277). Bochensui also uses the term epistemic authority as the "authority of the knowing person" whose answers to questions in the field of expertise are accepted by other persons (Bochensui, 1974). AK has at least two aspects: knowledge about the patient (patient-related $\mathrm{AK}$ ) and knowledge about the medically relevant facts, techniques, and so forth (medical AK). Here, we are primarily focused on patient-related aspects of AK. Patent-related AK means that relatives have privileged knowledge, or at least the capacity to attain it, concerning the beliefs, "world-view" and presumed wishes of the patient. These become relevant as soon as decisions are supposed to be justified with reference to the presumed wishes of the patient who no longer has the faculty of judgment (SAMS, 2005). ${ }^{8} \mathrm{AK}$ includes the assumption that relatives generally are in the best situation to express what a patient would wish if he or she was able to communicate his or her wishes; relatives are considered capable of speaking on behalf of the patient. This line of argumentation implies that the values and autonomy of the patient can be promoted through relying on a relative's voice (Arnold and Kellum, 2003). However, the degree to which this capability is prevalent among relatives may differ, although this is a matter of debate. 
To what degree physicians and nurses have patient-related AK is open to discussion. They may, but ceteris paribus do not generally have a high degree of patient-related AK regarding wishes relevant for making treatment-decisions. In EoL care, this depends particularly on their chances to get to know to the patient before he or she becomes unable to communicate. They may even have specific AK, if a patient did speak to them about his or her wishes before losing the faculty of judgment or consciousness. Conversely, physicians and nurses do have a high degree of authority of knowledge about medical and nursing care, diagnostic and treatment measures (medical AK), which is an area of knowledge about which the relatives usually have limited access.

The ability-dimension of the relatives' authority of knowledge can be understood as a cognitive capability. Are the relatives able sufficiently to understand the medical information? Do they adequately weigh risk and benefits of a specific treatment? Relatives who do not obtain sufficient understanding in this area will probably have difficulties exerting other types of authority in the decision-making process. People who lack the cognitive or emotional ability to make informed decisions are not regarded as adequate surrogates for a patient. This is also true from a moral point of view (Arnold and Kellum, 2003), which corresponds with our notion of the authority of decision-making. However, the question of whether a decision-maker possesses the ability and faculty of judgment together with the relevant knowledge, should not be limited to lay people such as relatives or patients, but has general relevance to all concerned (SAMS, 2005, pp. 12-13). Therefore, the authority of knowledge seems to be a very important, if not a necessary condition for exerting other types authority.

Authority of Good-Life Judgment (AGL). The relative's authority of making a judgment about the good life can be understood as an authority of judgment concerning a patient's well-being, his or her best interest or, more philosophically, the authority of making a eudaimonistic judgment (see Aristotle, 1985). AGL refers to the assumed capability of relatives to determine what "the best" for the patient would be- not in a medical sense, but in the sense of a "good life" and a "good dying process". Attributing this kind of authority to a relative requires justification: knowing the patient very well, having privileged insight into his or her recent motivations, being sufficiently "distanced" to avoid preoccupation by one's own preferences, and so forth. This authority refers to "the good" as an extra-moral value, relevant for and specific to the patient (but possibly with an underlying general idea of the good, e.g., a shared world-view or religious belief system). AGL can also be understood in relation to the "best interest" standard. Relatives may consider themselves privileged to make decisions in 
the (presumed) "best" interest of the patient—an attitude resembling the paternalistic approach—based on their knowledge about the patient's values, or their existing emotional bonds. However, this type of authority may be misleading in cases where relatives actually lack knowledge about the authentic values of the patient (Arnold and Kellum, 2003). Finally, AGL can be understood as determining the objective interest and well-being of the patient (SAMS, 2005, p. 13).

Authority of Decision-Making (AD). The authority of decision-making refers to the capability of relatives to make particular treatment decisions on behalf of the patient or to support the patient in the decision-making process. This means that relatives are taking on the function of a surrogate (with or without formal authorization). A special and clearly regulated case is the decision-making authority of parents regarding treatment of their children. $\mathrm{AD}$ can also be transferred to a physician, although relatives often prefer to share this authority with physicians (Heyland, Rocker, \& O'Callaghan et al., 2003). The idea of sharing the authority between clinical staff and family is rather popular in Switzerland (SAMS, 2005).

Whenever relatives wish to share decision-making, physicians should not reject this approach or delegate AD back to the relatives. Nevertheless, this may happen through verbal or non-verbal communication and can unintentionally lead to distress with the relatives, who, especially when involved in ICU care of a family member, experience high levels of stress in any case (Pochard, Azoulay, \& Chevret et al., 2001). Sharing the authority of decision-making and taking responsibility for the consequences of the agreed course of action may be quite burdensome for relatives.

Authority of Procedure (AP). The authority of procedure refers to the capability of determining the formal and organizational decision rules as well as the process of decision-making itself. Relatives rarely have AP at the bedside of a severely ill patient or in a health care institution. They may share $\mathrm{AD}$ or exert some specific aspects of procedural authority, if the institution and the staff support their participation in the decision-making process. AP can also be shared with a third-party in addition to the clinical staff, namely a consultant or a mediator (Agich, 1995). In Europe, ethics consultation typically is not seen as delegating AD to ethics consultants; rather, ethics consultants serve those entitled to make decisions as facilitators with specific knowledge and skills (Reiter-Theil, 2005).

Authority of Action (AA). The authority of action indicates that relatives can be addressed as people who are capable of relevant actions. They have intentions, and these intentions are accessible to them-contrary to a patient who is (temporarily or permanently) incapacitated. Often, the authority of decision-making and the authority of action coincide. However, if relatives 
are involved as actors, but deprived of the authority of decision-making, i.e., are not allowed to decide on behalf of the patient, a divergence occurs. The two types of authority should be distinguished conceptually because they may clash in practice. If relatives are understood as members of the unit of palliative care, authority of action, i.e., being able to do something for the patient, should never be denied. They must determine how far they feel capable of getting involved in practical care, be it at the bedside in the caring institution or at home.

\section{Conceptual confusions between dimensions and types of authority}

This approach to describing the roles of relatives in decision-making (DM) seems to provide a fruitful conceptual and theoretical model. Furthermore, the approach is also useful as a clinical tool; it identifies common confusions and conflicts related to the normative, ethical, and practical issues that arise in the involvement of relatives.

Confusions may occur within all types of authority as well as among the three dimensions. A specific confusion may prevail if there are doubts about the authenticity of the relatives' knowledge concerning the patient's wishes and interests (patient-related authority of knowledge), and if those doubts lead to questioning the right of the relatives to be involved in decisionmaking, instead of openly expressing the doubts. Furthermore, the relatives' capability to determine "the best" for the patient (authority of good-life judgment) may be confused with their (degree or lack of) understanding of the clinical facts (medically-related authority of knowledge). This confusion may be prevalent quite frequently and it may be difficult sufficiently to distinguish between "the best" in the sense of medical treatment, and "the best" in the sense of a good life. However, overlap and gray zones between the two concepts are possible if specific kinds of medical or nursing interventions are necessary to determine what is "the best" in the eudaimonistic sense is as it is represented by the relatives.

In these situations, the actual topic is categorized in the wrong "logical geography" (Ryle, 1965), if instead of using a common-sense language or a language of philosophy or ethics, a medical language system is applied. Therefore, it seems worthwhile to identify as precisely as possible what kind of "function" relatives have in the decision-making process and which types of authority they are exerting, in addition to how this is perceived by the clinical staff. We are most interested in looking more deeply into the question of which requirements may be necessary convincingly to realize the authority of relatives. A structured discussion and decision-making procedure that explicitly integrates the question about the roles relatives are fulfilling or should fulfill would not only contribute to theory, but also help 
in the practical setting. More specifically, legitimate criticism, e.g., about the relatives' authority of knowledge, could be distinguished from nonlegitimated doubts that are based on conceptual confusion. This may help to eliminate ethical problems that derive from non-moral conditions, or at least make it easier to cope with them. Another legitimate criticism is doubt about the presumed patient-related authority of knowledge of relatives in the case where circumstances indicate that the relatives do not have sufficient knowledge to judge the wishes and preferences of the patient. This includes the use of earlier statements by the patient in determining the presumed patient wishes.

In the ethical analysis we distinguish between "first order" and "second order" ethical problems. A "first order" ethical problem arises out of ethical reasons, while a "second order" problem is derived from specific triggers or contexts such as a lack of communication. For example, a conflict between the duties of respect for autonomy and the obligation to help cannot exclusively be solved by ideal communication. Even if an ideal discourse existed, the conflict between the obligations would persist. This situation thus constitutes a "first order"-or "real"-ethical problem. Real ethical problems are not limited to situations where the involvement of relatives in decision-making is neglected or missing. These problems may also arise when the involvement is ethically sound and, therefore, need to be treated differently from those which we call "second order" ethical problems. The latter problems result from stimuli other than ethical reasons, such as organizational insufficiencies, unpredictability of consequences, or undesired outcomes of indicated interventions.

\section{Results}

This section provides an overview of a systematic case series carried out on an intensive care unit; the overview includes information about the roles of the patient's relatives. Subsequently, we provide an in-depth report of case 3, and excerpts from the "table rounds" with deliberations on this case. Finally, the typology of authority will be applied to relevant quotes selected from the verbatim transcripts of the table rounds.

\section{Case Overview}

The case series covers ten ICU patients in whom treatment limitation was considered, discussed or decided due to unfavorable prognosis. We studied the criteria and procedural aspects of decision-making regarding the withholding or withdrawing of treatment. As a result, all ten patients died: 
two of them after being transferred to the ward or to another hospital. None of the patients were capable of making decisions at the time of the study.

Case 1: A 70-year-old female patient died four days after suffering from a subarachnoid hemorrhage leading to a massive brain edema. On the second day, no therapeutic measures were taken because prognosis was judged to be unfavorable. The relatives were informed regularly and agreed that the dying process should not be prolonged.

Case 2: A 20-year-old male patient had been involved in a car accident that caused severe head injuries. He was taken to the central hospital by helicopter ambulance where an emergency operation was carried out to remove a subdural hematoma. Despite maximal therapeutic efforts, brain pressure increased in excess of $80 \mathrm{~mm} \mathrm{Hg}$ in the hours following the operation because of the development of a massive brain edema. The physicians assumed that the patient was already brain dead, so all therapeutic efforts were stopped and the relatives were informed. The relatives, in particular the aunt of the patient, suggested the possibility of organ donation. During the first meeting with the relatives, the physicians in charge purposely did not respond to this suggestion. Instead, they decided to discuss it further in the next meeting after brain death diagnostics had been started. The team perceived the patient's aunt to be very dominant. The nurse in charge suggested that the aunt had taken over the mother's authority and suggested that the team take that concern into consideration. It first had to be checked whether the mother really agreed to the organ donation. During another meeting the relatives agreed to the organ donation although the patient did not have a donor card. The patient was diagnosed brain dead 48 hours after the accident. The patient donated the heart, liver, pancreas, and both kidneys.

Case 3: This case will be described in depth in section 4.2.

Case 4: A sprightly 77-year-old male cyclist was run over by a car, which caused fractures of the $4^{\text {th }}$ and $5^{\text {th }}$ cervical vertebrae leading to quadriplegia. On day two, the team decided not to treat the patient for aspiration pneumonia. The relatives played an important role in that decision by credibly reasoning that living with quadriplegia would not be compatible with the patient's presumed wishes. However, the medical team did not fully agree regarding the degree of the relatives' involvement. They also discussed whether the relatives should be allowed to decide if the oxygen content in the inhalation air should be lowered. Should they be burdened with such a decision? The patient died on day six following the accident after all therapeutic measures had been systematically withdrawn.

Case 5: A 70-year-old male patient suddenly complained about severe stomach pains. In a non-local hospital, a ruptured abdominal aortic aneurysm 
was diagnosed and the patient was taken to the central hospital immediately where an emergency operation was undertaken. Due to an occlusion of the left arteria carotis interna, a hemiparesis at the right side developed after the operation. It had to be expected that the patient would need permanent care and be dependent on a wheelchair. In this case, the relatives, thinking of all possible consequences, asserted that such a life would not correspond to the presumed wishes of the patient. As in case 4, all life-prolonging therapies were systematically withdrawn and the patient was transferred back to the original hospital. He died ten days after the start of the illness.

Case 6: A 35-year-old female patient had been severely injured as a front seat passenger involved in a car accident. She suffered severe head injuries and had to be resuscitated at the scene of the accident. The hypoxic brain damage that subsequently developed was so widespread that the patient was diagnosed brain dead six days after the accident. This development was foreseen directly after the accident, and the relatives were informed immediately that the chances of surviving were small. The patient carried a donor card and was considered for organ donation after being diagnosed brain dead. However, because of her past drug usage, her organs were not taken.

Case 7: An 80-year-old patient suffered from a myocardial infarction with rupture of the interventricular septum. An emergency operation was carried out, which was technically very difficult and time consuming. Blood pressure had to be effectively supported during the whole operation and an intra-aortic balloon counterpulsation needed to be inserted. Round the clock cardiovascular support was necessary in the days following the operation on the intensive care unit and could not be reduced. The patient's two sons only wanted to be informed about the course of the illness without getting involved in the decision-making process. On day 3 after the operation, the care team was unexpectedly presented with an advance directive, which stated that the patient did not wish any life-prolonging measures in case of severe illness. As a result, all cardiovascular support systems were withdrawn and the patient died shortly thereafter.

Case 8: A 65-year-old female patient suffered from a subarachnoid hemorrhage after the rupture of a cerebral aneurysm. She was operated on and started her slow recovery. In the days following the operation, a growing brain edema developed due to spasms of the brain vessels. As a last resort, a craniectomy was carried out to increase space for the brain. Her husband agreed that everything possible should be done to avoid later regret of not having taken all options. Nevertheless, he was afraid that his wife's injuries could result in neurological deficits. Despite the efforts, on day 11 after the incident she was diagnosed brain dead. 
Case 9: A 71-year-old female patient entered the hospital as an emergency case because her general condition had severely deteriorated and she had a fever. A pharyngeal abscess impaired by a mediastinitis was diagnosed, and she had to undergo surgery on two separate occasions. Subsequently, a septic shock developed that had to be treated using high doses of norepinephrine. Due to acute renal failure, continuous hemofiltration therapy was undertaken. The physicians realized that the patient's hands and feet continuously became darker. The increasing ischemia meant that both hands and forefeet had to be amputated. The relatives, one daughter and the patient's partner, were unable to cope with the situation. Although they contacted the clinical team from time to time, they rarely visited the patient. Due to the septic shock, the patient needed many infusions which caused an edema. The relatives found it hard to look at the patient and avoided conversation with the team. Yet, they were informed on a regular basis of the patient's condition, but were not involved in the decision-making process. The care team decided to withdraw all supporting therapies and to continue with palliative care. The patient died within several hours on day six after entering hospital.

Case 10: A 73-year-old patient was electively operated on due to abdominal aortic aneurysm. A few hours after the operation, the patient needed to be taken back to the operation theatre due to a thrombosis of one part of the y-prothesis. After this operation, he woke up very slowly and physicians realized that he could not move the right side of his body. This was due to an occlusion of the left arteria carotis interna, which led to severe ischemia in the brain areas supplied by the vessel. On day 4 after the operation, the medical team decided not to extend therapy. During the following days, certain therapies were withdrawn. The relatives suggested that the patient would not want to live in need of permanent care and dependent on a wheelchair. They participated in the decision-making and consented to the withdrawal of the respective therapies. Thirteen days after the operation, the patient was transferred to the ward, where he died six days later.

\section{Case 3}

A 50-year-old female patient was admitted to the emergency unit in hospital after an acquaintance stabbed her with a knife in the stomach and the left hand. The exact progression of events was not known. An operation had to be carried out due to injuries sustained to the small intestine. The patient was kept under supervision overnight in the monitoring ward and transferred to the general ward in the morning. Two days after the operation, the patient 
screwed her eyes during the visit of her husband, gasped for air, and collapsed unconscious. An emergency team was alerted immediately. The emergency team intubated the deeply unconscious patient and treated her low blood pressure. At no point in time had the patient suffered from cardiac arrest.

After this incident, the patient was treated on the intensive care unit for a total of 25 days. However, the reason why she lost consciousness could not be fully explained. Subsequently, acute respiratory distress syndrome (ARDS) developed, from which the patient died 28 days after being admitted to hospital. Prior to death, physicians had tried to reach sufficient blood oxygenation using all forms of treatment available (different forms of mechanical ventilation, change of body position, steroids, antibiotics, and so forth). Nevertheless, as bronchopleural fistula continued to develop on both sides in the lungs, no life-sustaining oxygen saturation could be reached despite ventilation with $100 \%$ of oxygen. Throughout this time, the patient was fed via gastric tube.

The patient was married and had one daughter. Her brother is a medical doctor and has a practice with a general practitioner. During the course of the illness, the relationship between the clinical team and the patient's brother became very difficult (see quotes $4,5,7$ and 8). He asked to be thoroughly informed about the treatment, in addition to demanding therapy options, e.g., using steroid therapy (see quotes 5 and 8). Furthermore, he requested that the patient be treated with Interferon (see quote 2). The clinical team rejected this because it had not yet been used in such illnesses and, therefore, would have been purely experimental. The brother continued to demand that everything possible be done for the patient. Also, he made blatant accusations against the team several times, most notably for treatment errors (see quote 5). He requested that his sister be transferred to another intensive care unit (see quote 5). The request was considered, but the patient was not in a condition to be transported. The patient's daughter suffered immensely because of the situation (see quotes 7 and 8), and the team advised her to seek help from the crisis intervention department. She followed the advice and, subsequently, her psychological state seemed to improve.

\section{Table rounds}

In the following section, selected quotes from the table rounds regarding case 3 are presented to illustrate how the role of the relatives was perceived by the clinical staff involved. (The table rounds were translated from the original Swiss German to English literally.) We also use the typology of 
authority and apply it to the involvement of the relatives in this case."

\section{Application of the typology of authority to the quotes of the table rounds}

Quote 1: AA: But I think that it's not really necessary that they always know what we're discussing, but, what we're discussing here, these are, er, also for us, foundations for decision-making among the specialists, or, pneumology, that also know how this develops, or ....

Here, two different aspects of authority of knowledge are involved: one that should provide a basis for ethical decision making (patient-related AK), and one that should provide a basis for "technical" decision making (medical AK). Ethically relevant issues (such as the presumed patient wishes or the evaluation of the expected consequences of a treatment) are not reserved for the discourse of the clinical experts alone, but also address those who are close to the patient, whereas "technical" decision-making relies on the specific authority of medical knowledge.

Quote 2: AA: So, the intern talked to him [patient's brother] yesterday and brought up the thing with the Interferon a little bit and so on. Er, but then, he didn't, didn't really react much to it and he, rather thought, um, that now it's time, that we need to talk about therapy withdrawal, actually. And that he would like to talk to the family ...."

This quote addresses the issues of authority of procedure: the brother participates in determining the content of the deliberations concerning the patient, and also to a degree tries to determine the procedure (e.g., that the question of withdrawing treatment should be discussed with the family first. However, it is important to note that the brother of the patient is a physician, who works as a general practitioner. While fulfilling the role of a relative, he uses his professional background to gain some authority of procedure as well.

Quote 3: AA: ... where the majority of opinion lies with the relatives. On the one hand, he can say no, that they are against reduction of therapy or at least in favor of suspending, or they, they want to withdraw. In that case, I think, we've got to think about that, um, or, but it's like, that we have to decide that at the end. It can't be that the relatives decide that in the end.

In this quote, the difference between the wishes of the relatives - or a type of (doubtful) authority of good life judgment-and the authority of decision-making is noticeable. At first, the topic is the relatives' wishes based on the authority of good life regarding whether a reduction of treatment might be "the best" for the patient. However, the objection of the

*Abbreviations from the quotes: $\mathrm{AA}=$ attending anesthesia; $\mathrm{AS}=$ attending surgery; $\mathrm{MD}=$ medical director; $\mathrm{I}=$ intern; $\mathrm{N}=$ nurse. Words referring to relatives are italicized. 
AA shifts the discussion to the question of who may make decisions about the actions under discussion (i.e., authority of decision-making).

Quote 4: AA: So, we've got, interesting, for the talk, the talk this afternoon with the relatives, 'cause they know, her brother maybe knows, what she [the patient] would have wanted. - AS: That's what I'm skeptical about. - N: Me too, has the brother got so much right to determine what's going to happen, I can't ...

The assertion of the AA is related to the authority of knowledge of the relatives, an authority that is questioned thereafter by the AS. The nurse, on the other hand, formulates doubts about the authority of decision-making or authority of action on the side of the brother.

Quote 5: AS: ...so at the beginning, only the brother came to the meeting, who, um...then the conversation escalated soon, because in the end it was not, for the brother, it wasn't about that like he sticks to the agreement that we decide what's going to happen, but then again, after a short time he started to investigate what allegedly goes wrong here and questioned the therapy, and then we stopped the meeting, um, and then he replied that he would make sure that she'll be transferred to the medical intensive care unit. ... um, shortly after the husband and daughter came, and they obviously hadn't been informed enough by the brother what the meeting was really about and also weren't fully informed about the, er, how the patient is really doing.

This quotation makes the problem within the family evident: the brother assumed for himself the decision-making authority by trying to decide on behalf of the family, with the husband and the daughter inadequately informed of the decisions that were the subject matter of the meeting. Lack of information leads to a decreased ability-dimension for authority of procedure. It should also be noted that what the patient would want and what the family may agree about are not necessarily the same.

Quote 6: N: Ah that psyche! If you don't do anything with her, that's a question of feelings, exactly as he said that he's got the feeling. Those are his feelings. If you don't do anything with her, you don't see anything on her, do you? They hardly touch her anyway; they've got hardly any contact with her. I tell them, you can touch her, you can talk to her."

The nurse describes the relatives' failure to maintain contact with the patient. This observation addresses a lack of understanding regarding the medical and existential situation of the patient, i.e., doubts of the ability of the relatives to contribute to DM.

Quote 7: N: ...lately I get the impression that we're going round in circles. It's getting more and more difficult with the relatives, especially with the daughter, and I realize that she's at the limit, with that, with the 
situation. And a brother, who keeps phoning in the morning, asks for an official medical report from us."

The daughter is at the limits of her ability to participate because of emotional distress. This makes the whole decision-making process with the relatives more difficult. On the other hand, the brother is heavily involved in the process. The way in which the nurse is talking about his attitude suggests that she doubts his right to the high degree of involvement he requests.

Quote 8: AS: I don't think that her brother, from what we've seen of him 'til now, if you look at everything, really is the person that thinks and talks in the interest of his sister. - AA: Yes, that's exactly why we want to know what the others think, not the brother, who talks, what the others, the husband, who now apparently came back to her, for whatever reason, says, maybe also the daughter, or, I mean she's really at the limit, what I can also understand after seeing the mother like that for three weeks, yes."

Again, the brother of the patient is perceived as a disturbing factor because the clinical team is not convinced that he represents the interests of the patient (authority of good-life judgment), nor that he functions as the spokesman of the family. The other relatives also need to be heard, which is difficult because of the family situation.

\section{Discussion}

The results of the presented case series, the single detailed case analysis, and transcript analysis illustrate the need for discussion about how relatives should be involved in EoL decision-making and what can be expected from their participation. It has also become evident that the need for clarification covers much more than the question of whether or not a relative has a legal right to act as a substitute decision-maker. As the case series documents, formal authorization of relatives (by a court or through the patient in an advance directive) is very rare in practice. Most relatives act within a gray zone where their actual rights - or obligations-to speak for the patient and the adequate way to involve them into EoL decision-making remain open to interpretation of those involved.

Under the present legal conditions in Switzerland (and also Germany), relatives who are not authorized as substitute decision-makers should be invited to contribute their knowledge about the presumed wishes of the patient, but are not to advocate their own preferences in the case. Legally, the final judgment and responsibility rest with the physicians: they have to decide how they will make use of the information provided by the relatives and which conclusions they draw. But the situation is more complex. Relatives generally lack education about these issues and have difficulties 
defining their role. General criteria and rules about an adequate procedure are lacking. As a consequence, there is uncertainty among the clinical staff about the adequate way to involve relatives; decisions about eventually limiting treatment at the end-of-life are not considered easy by physicians and nurses anyway. The uncertainty concerns ability and right to the decision-making process. Are relatives only providers of patient-related knowledge, or do they serve to determine what "the best" is for the patient? Should they be actively involved in the DM process, or even have an influence on the procedures of EoL decision-making? This uncertainty is not surprising as the normative-ethical situation is ambiguous. On the one hand, the present Swiss legal framework is rather restrictive, protecting the incapacitated patient from interference by third-parties, including unauthorized relatives. Protection from third-party interests certainly is justified by the principle of respect for patient autonomy. On the other hand, strong psychological and moral intuitions indicate that relatives should not be marginalized in decisions that have an existential meaning for their beloved-one and themselves; these intuitions are expressed in the draft version of the Civil Code revision, in which it is planned to give relatives more weight in EoL decisions concerning a family member. The increasing recognition of palliative care and the concept of the "Unit of Care" have strengthened the request that relatives should be adequately involved in caring for the patient. Appreciation for the relatives and their knowledge about the patient as a source for EoL decision-making has challenged the traditional notion of "doctor knows best", the widely spread opinion that clinical expertise even covers knowing the presumed patient wishes or determining the patient's "good life" or "best interest". Whereas this motto will be held valid for clinical judgment, it is not easily accepted "after paternalism" and after large projects, such as the SUPPORT study, which showed that doctors are not better at guessing the patient's presumed wishes than relatives (SUPPORT, 1995). Given the background of civil rights and liberal traditions - very much present in Swiss everyday life-decisions of existential significance, including personal preferences about one's own dying process, may not be subject to any expert opinion, not even the doctor's. The debate about whether relatives should be given more influence beyond guessing the presumed patient wishes is ongoing.

This ideal of civil independence must not be confounded with the factual capability of relatives in a given situation, where they may feel overwhelmed by the challenge to participate in EoL decision-making and to share responsibility for the consequences. Therefore, the preliminary communication about the draft of the Civil Code revision in this regard has stimulated concern. In our view, a model for orientation is needed to guide 
clinical staff and relatives through the demanding process of critical and terminal care, and about how to manage participation in decision-making. Practical ethics is needed to step in between the legal norms and the psychological or moral intuitions. In a post-paternalistic approach that respects the rights of the patients, but also appreciates the potential of caring relatives and their knowledge, the typology of authority presented here allows for clarification of basic issues and a diagnosis of the "ethical status" of a given constellation. It is supposed to provide a conceptual framework to help the clinicians efficiently to view the strengths and weaknesses of the decision-making process regarding the relatives' contribution. It should also help to prevent errors by assessing insufficient distinctions between a) asking relatives what they know about the patient's wishes, and b) stimulating or tolerating that relatives introduce their own preferences instead-or mix them up. The brief and fast approach of diagnosing the ethical status may also remind clinical staff that relatives should be involved in an adequate way. By relying on the authority of knowledge in the conversation with relatives explicitly, both sides can rely on a transparent, reasonable, not only subjective, criterion of what should be considered necessary in the DM process, i.e., authentic insight into the patient's preferences and values. The gain of this approach will hopefully be twofold: 1) to safeguard that the DM process and the patient benefit from the knowledge of relatives, and 2) that the relatives-who are in an emotionally demanding situation-are not overwhelmed by diffuse or heavy responsibilities that they cannot and should not bear. As a result, the transparent approach would also help clinicians to handle the involvement of relatives, which sometimes creates more challenges than the clinical management itself.

\section{Conclusion}

Patients, family, and clinical staff need to be educated about the complex and often ambiguous situation that relatives of incapacitated patients should be involved in DM. It seems evident that this should happen in an ethically informed manner. The typology of authority regarding the relatives' roles is suggested as a practical tool for diagnosing the "ethical status" of their participation in a certain decision-making process and analyzing "incomplete constellations" that require modification. In summary, the present legal framework, moral intuitions, and clinical routine are not congruent-the first is regarded as too restrictive towards unauthorized relatives (see the revision project), the second (relatives should have a say in existential issues) may overstretch the competence of relatives, and the third, clinical practice, is 
oscillating between the two poles. The reform of the Civil Code will be underway for several years to come, and it is still unclear to where exactly it will lead. In this period of transition, ethical guidelines and tools seem to offer the best approach towards some general orientation for individualized case management.

\section{Acknowledgements}

We thank the Swiss National Science Foundation for generous founding of the projects no. 3200-06849/1 and no. 3200-06849/2. This study is part of developing a validated medical ethics guideline for clinical practice; see SNF project no. 3200B0-113724/1. The study would not have been possible without the excellent collaboration with the clinical partners. We are grateful for the helpful comments on the legal situation from Professor Volker Dittmann. Parts of the manuscript were translated or edited by Piera Jones, BSC.

\section{NOTES}

1 "Those who are the focus of a plan of care. In hospice palliative care this is typically the patient and his/her family". Center to Advanced Palliative Care (2006): http://64.85.16.230/ educate/ content/ elements/ lexicon/ unitofcare.html

2 Different legal situations in the different countries were considered.

3 Vorentwurf für eine Revision des Zivilgesetzbuches, 25.6.2003, Eidgenössisches Justiz- und Polizeidepartement, Bern. (Draft, Revision of Civil Code, 06-25-2003, Federal Department of Justice and Police, Berne).

4 Herrschaft defined as "die Chance, für einen Befehl bestimmten Inhalts bei angebbaren Personen Gehorsam zu finden" (translation (SRT): the chance that certain persons will obey a specific order).

5 Cognitive-subjective abilities such as power or faculty of judgment and level of (relevant) knowledge are included.

6 The normative question which type of authority relatives should have is discussed in: Mertz M. Rolle und Funktion von Angehörigen in kritischen Entscheidungen am Lebensende. Ein Beitrag zur Modellentwicklung auf der Basis einer begrifflichen Problemanalyse. Einsendearbeit Nachwuchspreis Akademie für Ethik in der Medizin, 2005.

7 The typology is suggested for the sake of conceptual order, but does not yet imply that relatives actually have or should have such authority. Possible ethical justifications will be discussed later. 
8 The cited literature does not use the same concepts of authority we propose here.

\section{REFERENCES}

Agich, G.J. (1995). Authority in ethics consultation. Journal of Law, Medicine and Ethics, 23, 273-283.

Aristotle. (1985). Nichomachean ethics. T. Irwin (trans.). Indianapolis: Hackett Publishing Company.

Arnold, R.M. \& Kellum, J. (2003). Moral justifications for surrogate decision making in the intensive care unit: implications and limitations. Critical Care Medicine, 31 (5), 347-353.

Bartels, S., Parker, M., \& Hope, T. et al. (2005). Wie hilfreich sind "ethische Richtlinien" am Einzelfall? Eine vergleichende kasuistische Analyse der Deutschen Grundsätze, Britischen Guidelines und Schweizerischen Richtlinien zur Sterbebegleitung. Ethik in der Medizin, 17 (3), 191-192.

Beauchamp, T.L. \& Childress, J.F. (2001). Principles of biomedical ethics. New York: Oxford University Press.

Bochensui, J.M. (1974). Was ist Autorität? Einführung in die Logik der Autorität. Freiburg i. Br., Germany: Herder

Bühler, E. \& Reiter-Theil, S. (2004). Überleben - ein ethisch ambivalentes Therapieergebnis? In: Sass, H.M. and May, A.T. (eds.), Behandlungsgebot oder Behandlungsverzicht. Muenster: Lit Verlag, pp. 15-31.

Center to Advanced Palliative Care (2006): [On-line] Available: http://64.85.16.230/educate/content/elements/lexicon/unitofcare.html.

Eidelmann, L.A., Jakobsen, D.J. \& Pizov, R. et al. (1998). Foregoing lifesustaining treatment in an Israeli ICU. Intensive Care Med, 24, 162-166.

Fassier, T., Lautrette, A., \& Ciroldi, M. et al. (2005). Care at the end of life in critically ill patients: the European perspective. Current Opinion in Critical Care, 11, 616-623.

Foucault, M. (1991). Discipline and punish: the birth of the prison. London: Penguin Books.

Gerlach, H., Dhainut, J.F. \& Harbarth, S. et al. (2003). The PIRO concept: R is for response. Crit Care, 7, 256-259.

Giannini, A., Pessina, A. \& Tacchi, E.M. (2003). End-of-life decisions in intensive care units: attitudes of physicians in an Italian urban setting. Intensive Care Med, 29, 1902-1910.

Hentschel, R., Lindner K., \& Krüger M. et al. (2006). Restrictions of ongoing intensive care (RIC) in neonates - a prospective study. 
Pediatrics, 118 (2), 563-569.

Heyland, D.K., Rocker, G.M., \& O'Callaghan, C.J. et al. (2003). Dying in the ICU. Perspectives of family members. Chest: The Cardiopulmonary and Critical Care Journal, 124, 392-397.

Hurst, S., Perrier, A., \& Reiter-Theil, S. et al. (2006). European physicians' experience with ethical difficulties in clinical practice. Journal of Medical Ethics, 33 (1), 51-7.

Levy, M.M. (2001). Evaluating our end-of-life practice. Crit. Care, 5, 182183.

Mayring, P. (2000). Qualitative inhaltsanalyse. Forum Qualitative Sozialforschung / Forum: Qualitative Social Research, 1 (2). [On-line] Available: http://qualitative-research.net/fqs/fqs-d/2-00inhalt-d.htm.

Meyer-Zehnder,B., Pargger, H. \& Reiter-Theil, S. (2007). Ablauf von Therapiebegrenzungsentscheiden: Eine systematische Fallserie auf einer Intensivstation. Intensivmed, 44, 429-437.

Pochard, F., Azoulay, E., \& Chevret, S. et al. (2001). Symptoms of anxiety and depression in family members of intensive care unit patients: ethical hypothesis regarding decision-making capacity. Critical Care Medicine, 29, 1893-1897.

Reich, W.T. \& Jecker, N.S. (1995). Care/Care Ethics. In: Reich, W.T. (ed.), Encyclopedia of Bioethics. New York: Simon \& Schuster Macmillan, pp. 319-329.

Reiter-Theil, S. (1998). Answers to change: the problem of paradigm shift in medical ethics from the German standpoint. In: Tröhler, U., Reiter-Theil, S. (eds.) (in collaboration with E. Herych) Ethics codes in medicine. Foundations and achievements since 1947. Aldershot: Ashgate, pp. 257269.

Reiter-Theil, S. (2001). Ethics consultation in Germany. The present situation. Health Ethics Committee Forum, 13 (3), 265-280.

Reiter-Theil S. (2003). Balancing the perspectives. The patient's role in clinical ethics consultation. Medicine, Health Care and Philosophy. A European Journal, 6, 247-254.

Reiter-Theil, S. (2004). Does empirical research make bioethics more relevant? "The embedded researcher" as a methodological approach. Medicine, Health Care and Philosophy. A European Journal, 7, 17-29.

Reiter-Theil, S. (2005). Klinische Ethikkonsultation - eine methodische Orientierung zur ethischen Beratung am Krankenbett. Schweizerische Ärztezeitung, 86 (6), 346-351.

Ryle, G. (1965). The concept of mind. New York: Barnes \& Noble.

Swiss Academy of Medical Sciences (SAMS). (2004). Care of patients in the end of life. SAMS [On-line] Available: www.samw.ch. 
Swiss Academy of Medical Sciences (SAMS) (2005). Recht der Patientinnen und Patienten auf Selbstbestimmung. SAMS [On-line] Available: www.samw.ch.

The SUPPORT Principal Investigators. (1995). A controlled trial to improve care for seriously ill hospitalized patients. The study to understand prognoses and preferences for outcomes and risks of treatment (SUPPORT). JAMA, 274 (20), 1591-1598.

Weber, M. (1999). Wirtschaft und Gesellschaft. Tübingen, Germany: Mohr.

WHO (2006) [On-line] Available: www.who.int/cancer/palliative/definition/ en/.

Zientek, D.M. (2005). The Texas advance directives act of 1999: An exercise in futility? Health Ethics Committee Forum, 17 (4), 245-259. 